\title{
PERANCANGAN SISTEM PORTAL PARKIR OTOMATIS DENGAN COUNTER SEBAGAI PENANDA LAHAN PARKIR BERBASIS MIKROKONTROLER ATMEGA
}

16

\author{
Wahyu Indra Sukmana ${ }^{1}$, Citra Kurniawan ${ }^{2}$ \\ Sekolah Tinggi Teknik Malang \\ Jalan Soekarno Hatta 94 Malang \\ Email: indrakeceng.ik@gmail.com ${ }^{1}$, airakurniawan@gmail.com²
}

\begin{abstract}
Abstrak: Pertumbuhan kendaraan bermotor yang sedemikian pesat akhir-akhir ini menyebabkan kondisi yang tidak seimbang antara pertumbuhan kendaraan dengan lahan parkir yang tersedia, hal ini terlihat dengan semakin menyempitnya fasilitas tersebut khususnya di tempat-tempat umum seperti pasar, rumah sakit, pertokoan, perkantoran dan juga tempat-tempat pendidikan. Hal tersebut menimbulkan masalah dalam sistem transportasi suatu daerah, salah satunya menimbulkan kemacetan. Salah satu penyebab kemacetan adalah adanya permasalahan pada pengelolaan lahan pakir. Photodioda yang digunakan sebagai sensor yang menjadi masukan sistem, sedangkan motor dan 7 segment sebagai keluaran sistem. Sensor photodioda dapat mengidentifikasi benda dengan menyesuaikan panjang dan tinggi benda tersebut. Ketika benda menghalangi seluruh photodiodamaka sistem akan mengidentifikasi benda tersebut merupakan sebuah mobil yang kemudian akan membuka portal serta counting pada seven segment. Dari perancangan sistem ini, sistem dapat memberi informasi berupa jumlah lahan parkir yang masih dapat dipergunakan dan juga membuka portal secara otomatis dengan mengidentifikasi benda yang akan memasuki atau keluar dari lahan parkir.
\end{abstract}

Kata Kunci: sistem, portal, parkir, mikrokontroler, prototype.

\begin{abstract}
The rapid growth of motor vehicles in recent years has resulted in unbalanced conditions between vehicle growth and available parking lots, as seen by the narrowness of the facility especially in public places such as markets, hospitals, shops, offices and places -School. This causes problems in the transportation system of a region, one of which causes congestion. One of the causes of congestion is the problem of land management of pakir. Photodiode used as the sensor that becomes the system input, while the motor and 7 segment as the system output. The photodiode sensor can identify objects by adjusting the length and height of the object. When objects block the entire photodiodamaka system will identify the object is a car which then will open the portal and counting on the seven segment. From the design of this system, the system can provide information in the form of the amount of parking space that can still be used and also open the portal automatically by identifying objects that will enter or exit from the parking lots.
\end{abstract}

.Keywords: system, portal, parking, microcontroller, prototype.

\section{PENDAHULUAN}

Sesuai UU Republik Indonesia Nomor

22 Tahun 2009 tentang Lalu Lintas dan Angkutan Jalan, pengertian dari kendaraan adalah suatu sarana angkut di jalan yang terdiri atas kendaraan bermotor dan kendaraan tidak bermotor. Kendaraan bermotor merupakan setiap kendaraan yang digerakkan oleh peralatan mekanik berupa mesin selain kendaraan yang berjalan di 
atas rel. Kendaraan tidak bermotor adalah setiap kendaraan yang digerakkan oleh tenaga manusia dan/atau hewan.

Setiap kendaraan membutuhkan suatu tempat pemberhentian setelah sampai pada tempat tujuan. Tempat tersebut kemudian disebut sebagai ruang parki (Abubakar,1998). Ruang parkir tersebut akan terlihat efisien jika mampu menampung kendaraan sesuai yang dibutuhkan. Namun,pertumbuhan kendaraan bermotor yang semakin pesat akhir-akhir ini terutama pengguna kendaraan pribadi menyebabkan kurangnya lahan parkir yang tersedia menurut Nath dalam Imbiri (2016).

Angka jumlah kendaraan yang terus meningkat tidak diikuti dengan penambahan lahan parkiran sehingga tempat parkir terlihat semakin sempit (Pranata et. Al,2015). Penambahan ruang untuk lahan parkir tidak mudah untuk dilakukan, terutama pada tempat-tempat umum seperti mal,perkantoran, supermarket karena itu akan membutuhkan biaya yang cukup mahal. Penambahan ruang untuk dijadikan lahan parkir juga tidak bisa dijadikan alternatif untuk mengatasi masalah parkir, karena permasalahan lebih kepada kurangnya informasi yang diterima oleh pengguna kendaraan tentang ketersediaan lahan parkir yang kosong (Dipranoto,2010).

Keterlambatan informasi tentang lahan yang masih kosong diakibatkan karena sistem parkir yang digunakan masih bersifat manual. Petugas parkir pada pintu masuk tidak akan mengetahui secara langsung jika sudah tidak ada lahan parkir yang masih kosong. Petugas tersebut membutuhkan informasi tentang lahan parkir yang masih kosong dari petugas lain yang berada di dalam area parkir yang kemudian disampaikan kepada calon pengguna lahan parkir. Keterlambatan informasi dari petugas tersebut membuat calon pengguna lahan parkir harus meluangkan waktunya pada masalah antrian (Istiqomah,2013)

Dari masalah keterlambatan informasi tentang adanya lahan parkir yang masih kosong,pengelola parkir dapat memanfaatkan perkembangan teknologi yang diperkirakan memberikan kemudahan di dalam kehidupan sehari-hari,yaitu dengan menggunakan sistem yang membantu calon pengguna area parkir untuk memastikan adanya lahan parkir yang masih kosong serta dapat dibuat sistem yang secara otomatis memberikan informasi apabila ada kendaraan yang masuk atau keluar (Dipranoto,2010). Sistem tersebut biasa disebut dengan sistem parkir otomatis.

Sistem portal parkir otomatis masih dapat dikembangkan lebih lanjut untuk menginformasikan mengenai adanya lahan parkir yang kosong yang diharapkan dapat membantu calon pengguna lahan parkir saat mencari lahan parkir yang masih kosong. Hal tersebut diharapkan dapat mengurangi kemacetan dengan menciptakan 
pengelolahan lahan parkir yang lebih baik dengan memanfaatkan teknologi yang terus berkembang,terutama pada kota-kota besar yang memiliki angka pertumbuhan kendaraan bermotor yang cukup tinggi.

\section{METODE}

Metode yang digunakan dalam penelitian ini adalah metode Prototyp. Metode ini cocok digunakan untuk mengembangkan sebuah alat yang akn dikembangkan lebih jauh dengan cara membuat rancangan kilat yang selanjutnya akan dievaluasi

Prototype bukanlah suatu yang lengkap, tatapi sesuatu yang terus di evaluasi dan dimodifikasi kembali. Perubahan sering terjadi pada prototype untuk memenuhi segala kebutuhan. Pada saat yang sama pula dapat dilakukan pengembangan agar memenuhi kebutuhan.

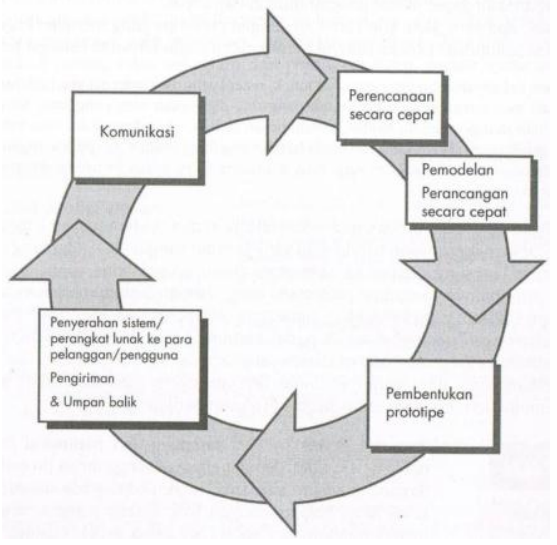

Gambar 1 Paradigma Pembuatan Prototype Sumber : Prassman (2010).

\section{HASIL DAN PEMBAHASAN}

\section{Source Code Inisialisasi}

Source code inisialisasi ditunjukan pada gambar berikut ini:

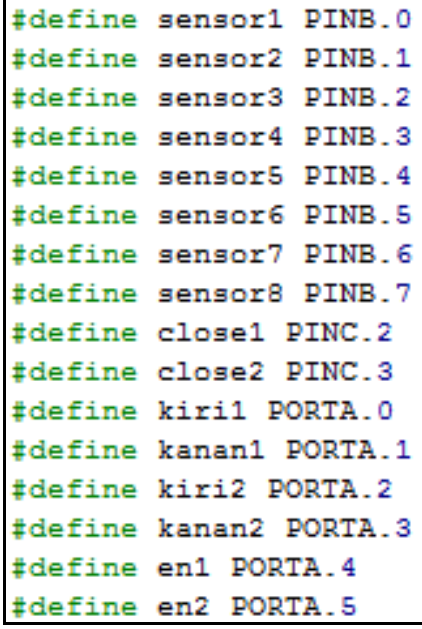

Gambar 2 Inisialisasi PORT dan PIN

Source code diatas berfungsi memberi nama pada setiap port yang digunakan untuk mempermudah pemanggilan port dan pin pada source code selanjutnya. Nama "sensor" diberikan untuk PIN dimana tempat sensor yang berada sebelum portal dihubungkan ke mikrokontroler. Nama "close" diberikan untuk PIN dimana tempat sensor yang berada setelah portal dihubungkan ke mikrokontroler, sedangnkan nama kiri dan kanan untuk PORT dimana motor driver dihubungkan ke mikrokontroler.

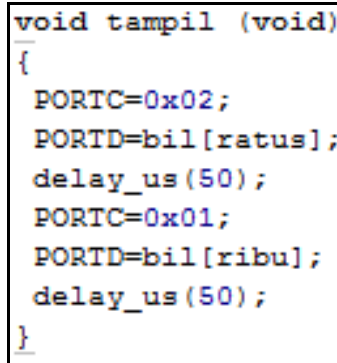

Gambar 3 Fungsi Tampilan pada 7 segment

Source code diatas digunakan untuk menginisialisasi fungsi penampilan pada 7 segment, sehingga jika pada source code selanjutnya dipanggil maka akan 
melakukan fungsi tersebut. Dimana PORTC yang digunakan untuk menampilkan angka pada sisi kiri diinisialisasi dengan nama "ratus" sedangkan untuk sisi kanan diinisialisasi dengan nama "ribu"

Source code pembacaan sensor untuk membuka portal

Source code untuk pembacaan sensor untuk membuka poral ditunjukan pada gambar berikut:

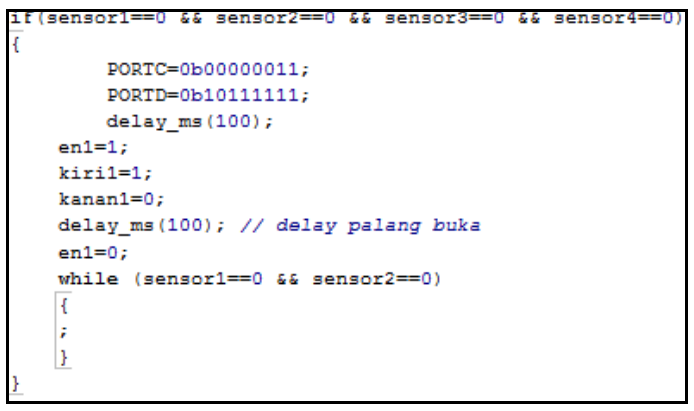

Gambar 4 source code pembacaan sensor untuk membuka portal pintu masuk

Source code di atas berfungsi untuk membaca masukan dari sensor, dimana saat keempat sensor terhalang maka mikrokontroler akan mengirimkan perintah ke motor driver untuk menghidupkan motor sebagai penggerak portal.

\section{Source code untuk menutup portal dan counter}

Source code untuk pembacaan sensor untuk membuka poral ditunjukan pada gambar berikut:

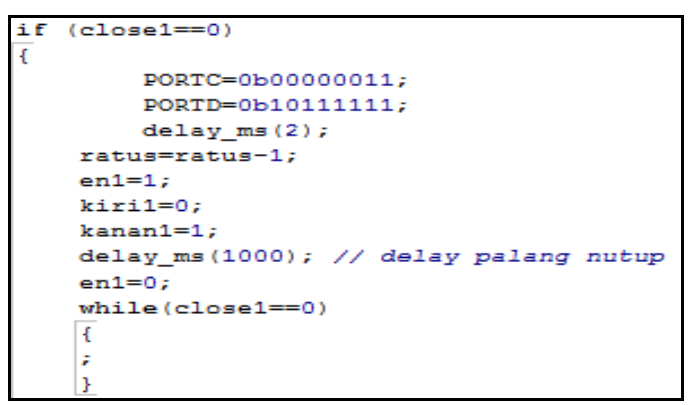

Gambar 5 Source code penutup portal Source code diatas berfungsi sebagai penutup portal dan sebagai counter untuk mengurangi jumlah lahan parkir yang masih tersisa yang ditunjukan melalui 7 segment

\section{Perancangan Prototype Sistem portal parkir}

Perancangan prototype dilakukan setelah semua bagian selesai dibuat. Pada portal parkir otomatis ini terdapat dua pintu yaitu pintu masuk dan keluar. Masingmasing pintu terdapat satu (1) motor, lima (5) photodioda. Empat (4) photodioda diletakkan sebelum portal untuk membuka portal, sedangkan satu (1) photodioda diletakkan setelah portal untuk menutup. Untuk menginformasikan lahan parkir yang kosong ditampilkan pada 7 segment. Setelah setiap komponen sudah diletakan pada posisi-posisinya, selanjutnya menyambungkan setiap kompone pada mikrokontroler maka prototype siap untuk diuji coba. Gambar di bawah ini merupakan gambar prototype keseluruhan: 


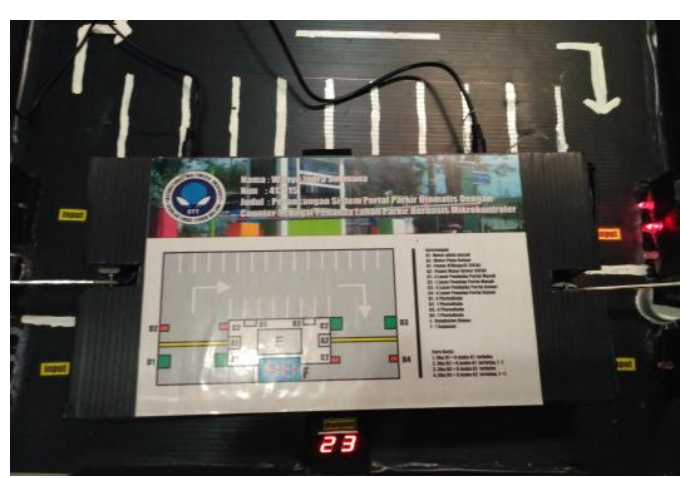

Gambar 6 Hasil jadi prototype sistem portal parkir

\section{PENGUJIAN PROTOTYPE}

Pengujian prototype dilakukan untuk mengetahui apakah prototype sudah bekerja dengan baik atau tidak. Indikator yang dipakai adalah respon dari setiap keluaran sistem yaitu motor dan 7 segment. Hasil pengujian keseluruhan prototype dapar dilihat pada tabel berikut ini :

Tabel 1 Hasil pengujian keseluruhan prototype

\begin{tabular}{|c|c|c|c|c|c|}
\hline \multicolumn{4}{|c|}{ Kondisi } & \multirow[b]{2}{*}{$\begin{array}{c}\text { mot } \\
\text { or }\end{array}$} & 7 \\
\hline $\begin{array}{l}\text { Phot } \\
\text { odio } \\
\text { da } 1\end{array}$ & $\begin{array}{l}\text { Phot } \\
\text { odio } \\
\text { da } 2\end{array}$ & $\begin{array}{l}\text { Phot } \\
\text { odio } \\
\text { da } 3\end{array}$ & $\begin{array}{l}\text { Phot } \\
\text { odio } \\
\text { da } 4\end{array}$ & & $\begin{array}{l}\text { seg } \\
\text { me } \\
\text { nt }\end{array}$ \\
\hline $\mathrm{X}$ & $\mathrm{x}$ & $\mathrm{x}$ & $\mathrm{x}$ & - & - \\
\hline V & $\mathrm{x}$ & $\mathrm{X}$ & $\mathrm{x}$ & - & - \\
\hline V & $\mathrm{v}$ & $\mathrm{x}$ & $\mathrm{x}$ & - & - \\
\hline $\mathrm{V}$ & $\mathrm{V}$ & $\mathrm{v}$ & $\mathrm{x}$ & - & - \\
\hline $\mathrm{v}$ & $\mathrm{v}$ & $\mathrm{v}$ & $\mathrm{v}$ & $\begin{array}{l}\text { ber } \\
\text { ger } \\
\text { ak }\end{array}$ & $\begin{array}{l}\text { cou } \\
\text { nti } \\
\text { ng }\end{array}$ \\
\hline
\end{tabular}

Keterengan :

\section{$X$ : Sensor tidak tersinari}

\section{$\mathrm{V}:$ Sensor tersinari}

- : tidak ada respon

Dari pengujian seluruh prototype didapat hasil bahwa sistem portal parkir sudah bekerja sesuai dengan yang diharapkan. Motor dan 7 segment akan merespon jika kondisi ke 4 (empat) sensor photodioda terhalang. Berikut adalah kondisi saat mobil mainan menutupi sensor photodioda serta respon dari motor dan 7 segment:

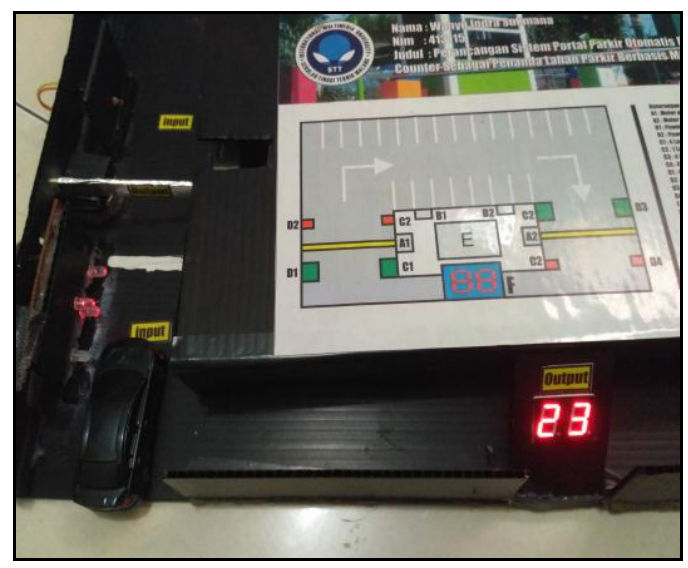

Gambar 7 kondisi satu sensor terhalang

Gambar di atas menunjukan kondisi satu sensor terhalang sehingga tidak ada respon dari motor maupun 7 segment

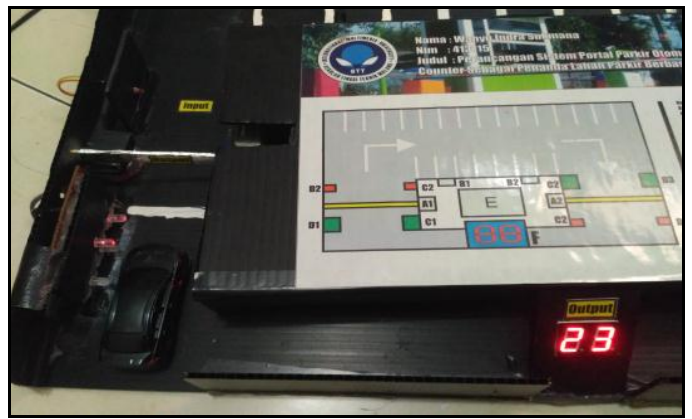

Gambar 8 kondisi dua sensor terhalang

Gambar di atas menunjukan kondisi dua sensor terhalang dan tidak ada respon dari portal maupun 7 segment 


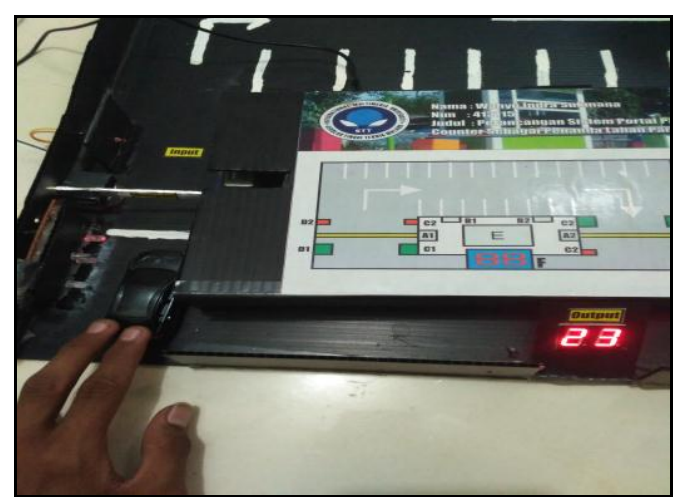

Gambar 9 kondisi tiga sensor terhalang

Gambar di atas menunjukan kondisi tiga sensor terhalang dan tidak ada respon dari motor maupun 7 segment

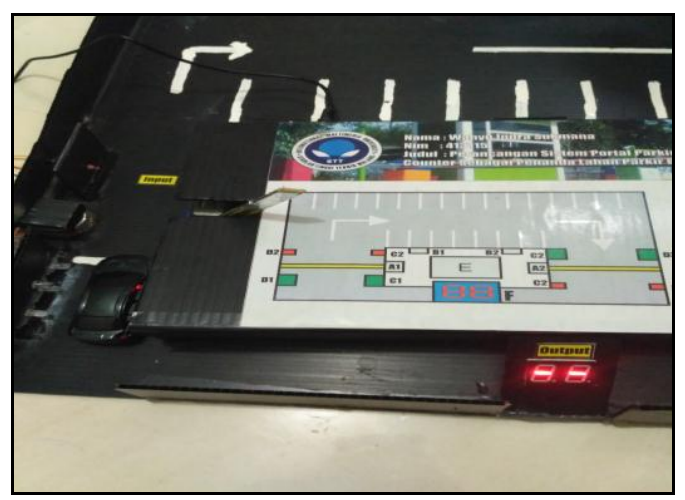

Gambar 10 kondisi empat sensor terhalang dan portal ternbuka

Gambar di atas

menunjukan kondisi dimana empat sensor terhalang yang kemudian masukan tersebut diterima oleh mikrokontroler untuk dilanjutkan ke motor driver dan 7 segment merupakan keluaran sistem. Motor sebagai penggerak portal akan bergerak searah jarum jam atau membuka portal sedangkan tampilan pada 7 segment akan berubah menjadi “--" seperti pada gambar diatas.

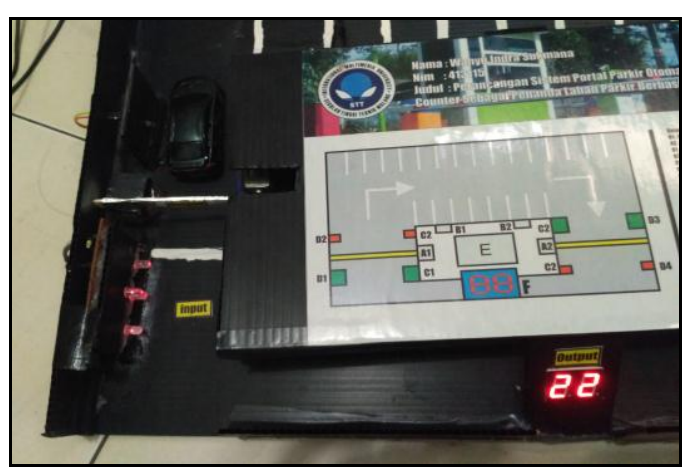

Gambar 11 kondisi portal tertutup dan counting

Gambar di atas menunjukan dimana sensor setelah portal terlewati atau terhalang oleh mobil sehingga mikrokontroler dengan otomatis memberikan perintah kepada motor untuk bergerak menutup portal dan 7 segment mengurangi jumlah lahan yang tersisa karena adanya mobil yang memasuki lahan parkir.

\section{KESIMPULAN DAN SARAN}

\section{Kesimpulan}

Berdasarkan hasil dari tahapan perancangan sistem portal parkir otomatis dengan counter sebagai penanda lahan parkir berbasis mikrokontroler, maka diambil kesimpulan sebagai berikut:

1. Sistem portal parkir otomatis telah bekerja seperti yang diharapkan.

2. Sensor photodioda dapat mengidentifikasi benda yang menghalangi merupakan mobil dengan menyesuaikan tinggi dan panjang benda tersebut

3. Sistem portal parkir otomatis dapat membantu pengolahan lahan atau tempat parkir yang masih 
mengandalkan tenaga manusis (manual)

4. Keluaran sistem pada 7 Segment yang berupa informasi jumlah lahan parkir yang masih tersisa dapat membantu calon pengguna lahan parkir mengetahui adanya lahan parkir yang dapat dipergunakan.

\section{Saran}

Rancang portal parkir otomatis ini masih memiliki kekurangan. Diharapkan pada penelitian selanjutnya dapat dikembangkan agar menjadi lebih baik. Saran untuk peneliti selanjutnya dari penelitian ini adalah sebagai berikut :

1. Penggunaan LASER pada sistem ini memiliki kekurangan yaitu LASER tersebut cepat panas sehingga diharapkan mengganti transmiter untuk sensor dengan komponen yang lain.

2. Penambahan sensor berat akan lebih baik dalam mengidentifikasi benda sebagai sebuah mobil.

\section{DAFTAR RUJUKAN}

Alfareza, Rexi Kurniawan. 2016. Kendali Pintu Bendugan Air Otomatis Menggunakan Sensor Ultrasonik Ping Berbasis Arduino Mega.TugasAkhir.

TeknikElektronika. Politeknik Negeri Sriwijaya. Palembang

Antonisfia, Yul. Irmansyah, Muhammad. 2013. Pintu Portal Otomatis Berbasis Teknologi
Progammable Logic Device (PLD). Politeknik Negeri Padang, Padang: Jurnal

Damayanti, Niken. 2008. Perancangan Aplikasi Sistem Informasi manajemen Widyaiswara berbasis WEB dalam rangka pengembangan e'Goverance di Pusdiklat Departemen PU. Tesis. Teknologi Informatika. Program Magister Universitas Indonesia. Depok

Dipranoto, AlfanRachman. 2010. Penghitung Jumlah Kendaraan

Pada Area Parkir Dengan Mikrokontroler AT89S51.

Universitas Gunadarma, Depok.

Earchaiiha. 2016. Aplikasi Keypad 4x3 dan Selenoid Door Lock Sebagai Pengaman Pada Brankas Berbasis Mikrokontroler ATmegal6. Tugas Akhir. Teknik Elektronika. Politeknik Negeri Sriwijaya. Palembang

Fadhil, Muhammad Idzar. 2014. Pengaruh Kepemilikan Kendaraan Pribadi Terhadap Ketersediaan Lahan Parkir. Skripsi. Perencanaan Wilayah dan Kota. Universitas Tanjungpura. Pontianak

Galuhirawan. Makalah ATmegal6.

(Online),

(https://id.scribd.com/doc/249846

322/Makalah-ATMega16, diakses 27 Juni 2017) 
Imbiri, Freeon Alkapon. Nandang Taryana.

Decy Nataliana. 2016. Implementasi Distem Perparkiran Otomatis dengan Menentukan Posisi Parkir Berbasis RFId. ELKOMIKA. 4. 1. Hal 31-46

Irawan, Joni. 2014. Rancang Bangun Alat

Pemberi Pakan Burung Otomatis Berbasis Mikrokontroler ATmega 16 dengan SMS Gateway. TugasAkhir. TeknikKomputer. PoliteknikNegeriSriwijaya.

Palembang

Istiqomah, DyahSiti. 2013. Prototipe Counter Kendaraan Diruang Parkir Berbasis Mikrokontroler AT89S51. Makalah disajikan dalam seminar riset FTI UNSA nasional informatika dan computer. Maret

Mariai, Jenifer Rian. 2016. Analisis Kapasitas Ruang Parkir Kampus IV Universitas Atma Jaya Yogyakarta. Skripsi. Teknik Sipil. Universitas Atma Jaya Yogyakarta. Yogyakarta

Maroekh, Mario William. 2017. Analisis Kebutuhan Ruang Parkir Rumah Sakit Umum Prof Dr W.Z.JOHANNES Kota Kupang, Nusa Tenggara Timur. Skripsi. Teknik Sipil. Universitas Atmajayayogyakarta. Yogyakarta

Murti, Sri, 2016. Perancangan Sistem Informasi Remainder Monitoring Data PO Pada PT Makmur Abadi
Semesta Tangerang. (Online), (https://widuri.raharja.info/index. php/SI1211474238\#Definisi_Pera ncangan_Sistem, diakses 27 Juni 2017)

Nufus, Afiatun. 2016. Perancangan Sistem Informasi Pemasaran Melalui Website Pada Anggrek Souvenir Palembang.TugasAkhir.Administ rasiBisnis.PoliteknikNegeriSriwij aya. Palembang

Peraturan Pemerintah Republik Indonesia Nomor 43 Tahun1993 Tentang Prasarana dan Lalu Lintas Jalan Pranata,Ardianto.SyaifulNurArif,

Yusnidah.2015. Perancangan Prototipe Sistem Parkir Cerdas Berbasis Mikrokontroler Atmega8535. SAINTIKOM. 14/2. Mei. Hal 131-140

Purnomo, Eko. 2015. Mikrokontroler AVR ATMEGA32. (Online). (http://www.nulisilmu.com/2015/09/mikrokontroler -avr-atmega32.html, diakses 27 Juni 2017)

Satria, Regi. 2011. Relay. (Online).(https://id.scribd.com/do c/73462710/Pengertian-RelayElectronika, diakses 8 Juli 2017) Simanjuntak, Nova Avrilia. 2016. Rancangan Monitoring Sirkulasi dan Stabilitas Suhu Ruangan Dengan Tampilan PC Berbasis ATMEGA 8535.Skripsi. 
FisikaEkstensi. Universitas

Sumatra Utara. Medan

Sugiyono. 2016. Metode Penelitian

Kuantitatif, Kualitatif, dab $R \& D$.

ALFABETA. Bandung

Undang-UndangRepublik Indonesia Nomor

22 Tahun 2009 Tentang Lalu

Lintas dan Angkutan

Winarsih, Irda. \& Reza Mahendra. 2009.

$\begin{array}{lll}\text { Sistem Parkir } & \text { Otomatis } \\ \text { Menggunakan } & \text { FRId } & \text { Berbasis } \\ \text { Mikrokontroler } & \text { AT89S51. } & \text { JEtri.8/02, Februari.hal 21-36 }\end{array}$

JEtri.8/02, Februari.hal 21-36 